\title{
Green synthesis of silver nanoparticles using leaf extract of Lantana camara and its antimicrobial activity
}

\author{
Narahari Narayan Palei, S. Ramu, V. Vijaya, K. Thamizhvanan, Anna Balaji \\ Department of Pharmaceutics, Sree Vidyanikethan College of Pharmacy, Tirupati, Andhra Pradesh, India
}

\begin{abstract}
Introduction: To synthesize silver nitrate nanoparticles (AgNPs) using aqueous leaf extracts of Lantana camara as a reducing agent and evaluates its antimicrobial activity. Materials and Methods: $L$. camara extract acts both reducing agents as well as capping agent. Fourier-transform infrared (FT-IR) study was used for identifying the compounds responsible for the reduction of silver ions, the functional groups present in the plant extract. Various techniques used to characterize synthesized nanoparticles are dynamic light scattering, transmission electron microscopy (TEM), energy diffraction X-ray, and ultraviolet-visible (UV Vis) spectrophotometer were performed to characterize synthesized AgNPs. Results and Discussion: From the FTIR study, it was confirmed the presence of some functional groups capping the AgNPs. UV-Vis spectrophotometer showed an absorbance peak in the range of 436-446 nm. The average particle size of the prepared AgNPs was found to be $86 \mathrm{~nm}$. In addition, the antimicrobial activity of prepared AgNPs was found to be higher than plain extract using various Grampositive and Gram-negative bacteria. Conclusions: From the results, it can be concluded that green synthesis of AgNPs from L. camera extract is easy, fast, one step, eco-friendly, and alternative conventional methods. The synthesized AgNP preparations from L. camara leaf extract show potential for application as broad-spectrum antimicrobial agents.
\end{abstract}

Key words: Antimicrobial studies, energy diffraction X-ray, Lantana camara, Silver nanoparticles, transmission electron microscopy

\section{INTRODUCTION}

$\mathrm{D}$ ifferent types of techniques are used to synthesize the silver nanoparticles such as chemical reduction, ${ }^{[1]}$ electrochemical, ${ }^{[2,3]}$ photochemical, ${ }^{[4]}$ biological, and physical methods. ${ }^{[5]}$ Methods for the biosynthesis of nanoparticles have been developed using either biological microorganisms such as bacteria ${ }^{[6]}$ and fungus ${ }^{[7]}$ or plant extract. ${ }^{[8,9]}$ The biosynthetic method for nanoparticle preparations has appeared as a straightforward and possible alternative to more complex chemical synthetic methods. Among these, green synthesis is widely used due to its eco-friendly nature and cost-effectiveness. Green synthesis means, which involves nanoparticles that are obtained by a combination of metal salts and plant extracts to obtain nanoparticles. In this method, reducing agent and capping agent properties were shown by plant extract itself and no need of the addition of any harmful chemical substance for reduction of metal. Microorganisms such as bacteria and fungus can be used for nanoparticle synthesis, but rate of reaction is slow compared to green synthesis. ${ }^{[10]}$ Chemical and physical methods are somewhat harmful to human because they need chemical substances for reduction metal into nanomaterial. In nanotechnology, various types of metals have been used for the synthesis of nanoparticles such as copper, ${ }^{[1]]}$ zinc, ${ }^{[12]}$ gold, ${ }^{[13,14]}$ and silver. ${ }^{[15-17]}$ Among these, silver was mostly preferred metal in the field of nanotechnology and nanomedicine due to its unique properties such as good conductivity, chemical stability, catalytic activity, and antimicrobial activity against bacteria and eukaryotic microorganisms. ${ }^{[18]}$ Due to that reason, in the present work, silver was used as a nanomaterial. Silver nanoparticles are widely used in various fields, especially in pharmaceutical sciences which include treatment of cancer,

\section{Address for correspondence: \\ Narahari Narayan Palei, Sree Vidyanikethan College of Pharmacy, Tirupati, Andhra Pradesh, India. \\ E-mail: narahari.palei@gmail.com}

Received: 28-09-2019

Revised: 06-03-2020

Accepted: 18-03-2020 
skin diseases, and ulcerative colitis. Factors such as time of reaction, temperature, $\mathrm{pH}$, and influences the nanoparticles obtained using plant extract. The plant Lantana camara Linn. (Verbenaceae) is an ornamental herb. It is found in South India, America, and Africa, mostly native to subtropical and tropical countries. The number of species is available with genus Lantana. Some species of Lantana are Lantana trifolia, Lantana salvifolia Jacq., and Lantana indica Roxb.; these leaves are rich in various chemical constituents such as triterpenes, glycosides, steroids, flavonoids, and essential oils. ${ }^{[19,20]}$ The plant contains various medicinal properties and used in the treatment of skin diseases such as dermatitis, itching, scabies, leprosy, and chickenpox. In the present work, L. camara (also known as red sage) leaf extract was used to synthesize silver nanoparticles (silver nitrate nanoparticles [AgNPs]) for antimicrobial studies.

\section{MATERIALS AND METHODS}

\section{Materials}

All chemicals, solvents, and media used in this study were of analytical grade and purchased from HiMedia (Mumbai).

\section{Methods}

\section{Collection of leaves and preparation of plant extract}

Fresh leaves of L. camara Linn. were collected from the local area of Tirupati, Andhra Pradesh. Collected leaves were washed thoroughly under running tap water for 2-3 times. The plant extract was obtained by cold maceration method. Twenty-five grams of washed leaves were kept in a $250 \mathrm{ml}$ beaker to that add $50 \mathrm{ml}$ of distilled water and boiled in a water bath for $30 \mathrm{~m}$ by maintaining a temperature between 40 and $50^{\circ} \mathrm{C}$. The extract was cooled down and filtered the solution with the help of the Whatman filter paper and stored in a refrigerator for future use.

\section{Phytochemical screening}

Phytochemical screening of $L$. camara leaf extract was performed to determine the presence of phytoconstituents. ${ }^{[21]}$

\section{Green synthesis of silver nanoparticles (AgNPs)}

A hundred milliliters each of different concentrations (1-5 mM) of silver nitrate solution were prepared in an Erlenmeyer flask. Then, 1, 2, 3, 4, and $5 \mathrm{~mL}$ of plant extract were added separately to $10 \mathrm{~mL}$ of silver nitrate solution keeping its concentration at $1 \mathrm{mM}$.

\section{Fixation of different parameters}

The reaction was observed at different time intervals. The reaction was observed using different concentrations of silver nitrate ( $1 \mathrm{mM}, 2 \mathrm{mM}, 3 \mathrm{mM}, 4 \mathrm{mM}$, and $5 \mathrm{mM})$ and varying leaf extract solution (1-5 mL) for synthesizing AgNPs and measured their absorbance.

\section{Characterization of Synthesized Silver Nanoparticles}

\section{Ultraviolet-visible (UV Vis) spectrophotometer}

UV-Vis spectral analysis was done using a UV-Vis spectrophotometer (UV-1800, Shimadzu, Japan). UV Vis absorption spectrophotometer with a resolution of $1 \mathrm{~nm}$ between 200 and $800 \mathrm{~nm}$ was used.

\section{Fourier-transform infrared (FT-IR) studies}

FTIR analyses were carried out using a Cary 630 FTIR spectrometer (Agilent Technologies, USA). To establish this point, comparisons were made between the spectrum of the extract and AgNPs. FT-IR was employed to analyze the samples in the range of $4000-600 \mathrm{~cm}^{-1}$ at room temperature.

\section{Particle size}

Dynamic light scattering (DLS) (Horiba SZ 100) was utilized to determine the average particle size of synthesized silver nanoparticles.

\section{Transmission electron microscopy (TEM) studies}

TEM (Jeol/JEM 2100, Jeol, Tokyo, Japan) was employed to study the morphology of AgNPs dispersion. One drop of diluted AgNPs dispersion was kept on a copper grid and for contrast enhancement, one drop of $2 \% \mathrm{w} / \mathrm{v}$ aqueous solution of phosphotungstate acid was used.

\section{Energy diffraction X-ray (EDAX) studies}

EDAX (OXFORD XMX N) was employed to study the distribution of the elemental composition of AgNPs.

\section{Assessment of Antimicrobial Assay}

\section{Test microorganisms}

The antimicrobial activity of prepared nanoparticles was studied using the diffusion method with the help of various Gram-positive and Gram-negative bacteria. In the present study, four different microorganisms such as Escherichia coli, Bacillus subtilis, Staphylococcus aureus, and Putida vulgaris were used. The pure cultures of microorganisms were prepared by adding loopful of each bacterium, which are maintained in nutrient agar slants, were added into $25 \mathrm{ml}$ of the fresh nutrient bath, and then kept the flasks in the incubators for better growth for at least $24 \mathrm{~h}$.

\section{Antimicrobial activity}

To prepare nutrient agar by dissolving $14 \mathrm{~g}$ of nutrient agar in $500 \mathrm{ml}$ of distilled water and was autoclaved for $30 \mathrm{~m}$. 
Then poured into the Petri plates and allowed it to solidify, after that spread anyone microorganism with the help of L-rod. Now make a cavity, not more than three cavities per plate, by maintaining at least a $1 \mathrm{~cm}$ gap between each cavity with the help of borrow. AgNP samples were placed with the help of a micropipette and kept in an incubator at $37^{\circ} \mathrm{C}$ for $24 \mathrm{~h}$. Afterward zone of inhibition was measured in $\mathrm{mm}$. The antibacterial activity was determined based on the inhibition zone around the disc impregnated with plant extract and synthesized AgNPs.

\section{RESULTS AND DISCUSSION}

\section{Phytochemical Screening}

Phytochemical screening of $L$. camara leaf extract was determine qualitatively and is depicted in Table 1 . The results reveal the presence of alkaloids, phenolics, flavonoids, tannin, saponin, terpenoids, phlobetanin, and coumarine.

\section{UV-Vis Spectroscopy}

Different amount $(1-5 \mathrm{~mL})$ of plant extract was added to $10 \mathrm{~mL}$ of $1 \mathrm{mM}$ aqueous solution of silver nitrate and kept in an incubator at room temperature. The color of extract containing silver nitrate solution was changed from light green to yellowish-brown and finally to colloidal brown [Figure 1] within reaction duration, indicating the formation of silver nanoparticles. The color change of the solution from green to reddish-brown due to excitation of surface plasmon vibrations in silver nanoparticles. ${ }^{[22]}$ In addition, different concentrations of silver nitrate and L. camara leaf extract and different time duration were used for synthesizing AgNPs. The synthesized AgNPs were analyzed by UV-Vis spectrophotometer and observed the lambda max at 436$446 \mathrm{~nm}$, similar to those reported in literature.

The color change is the primary sign for the formation of a nanoparticle because of the plasmon resonance phenomenon. Nanoparticle formation can be detected using UV-Vis

Table 1: Phytochemical screening of aqueous leaf extract of Lantana camara

\begin{tabular}{lc} 
Phytochemicals & Aqueous extract \\
\hline Carbohydrates & + \\
Alkaloids & + \\
Tannins & + \\
Proteins & - \\
Flavonoids & - \\
Steroids & - \\
Saponins & + \\
Amino acids & - \\
Cardiac glycosides & + \\
\hline
\end{tabular}

spectrophotometer [Figure 2a]. Silver nitrate of 1-5 mM concentrations was added separately to $1 \mathrm{ml}$ of plant extract for synthesizing AgNPs and increased the intensity of absorption peak by increasing silver nitrate concentration [Figure 2d]. The intensity of color and absorption peak of AgNPs was increased by increasing the concentration of leaf extract [Figure 2c]. The intensity of color and wavelength was increased, maybe due to the excitation of the surface plasmon resonance. Thus, a higher concentration of extract nanoparticles exhibits dark brown color with a maximum peak height. The synthesis of AgNPs was conducted by taking different concentrations of the extract with $1 \mathrm{mM}$ of silver nitrate at different time intervals such as $10 \mathrm{~m}, 20 \mathrm{~m}, 30 \mathrm{~m}, 1 \mathrm{~h}, 2 \mathrm{~h}, 3 \mathrm{~h}$, and $4 \mathrm{~h}$ and recorded the UV-Vis spectra [Figure 2b]. At $445 \mathrm{~nm}$, the maximum absorption peak was recorded in the UV-Vis spectrophotometer. By visual identification, we confirmed that formation nanoparticles occur rapidly within 20 min with the help of plant extract, which acts as a reducing agent. ${ }^{[23]}$

\section{Particle Size}

The particle size of AgNPs was found to be $86 \mathrm{~nm}$. The size distribution histogram of the DLS of AgNPs is depicted in Figure 3a.

\section{TEM Study}

TEM was carried out to confirm the size and shape of the silver nanoparticles. From the study, it clearly shows

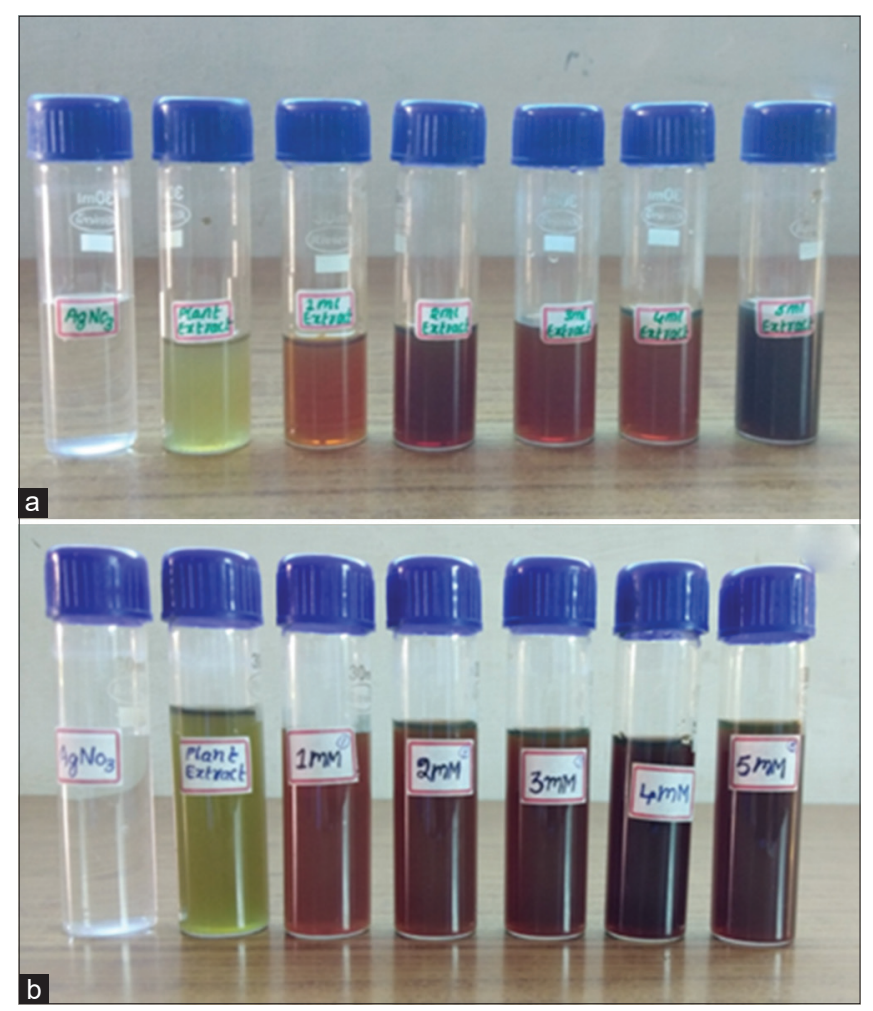

Figure 1: Photomicrography of synthesized silver nitrate nanoparticles with (a) different volume $(1-5 \mathrm{~mL})$ of the extract; (b) different concentrations (1-5 mM) of $\mathrm{AgNO}_{3}$ 

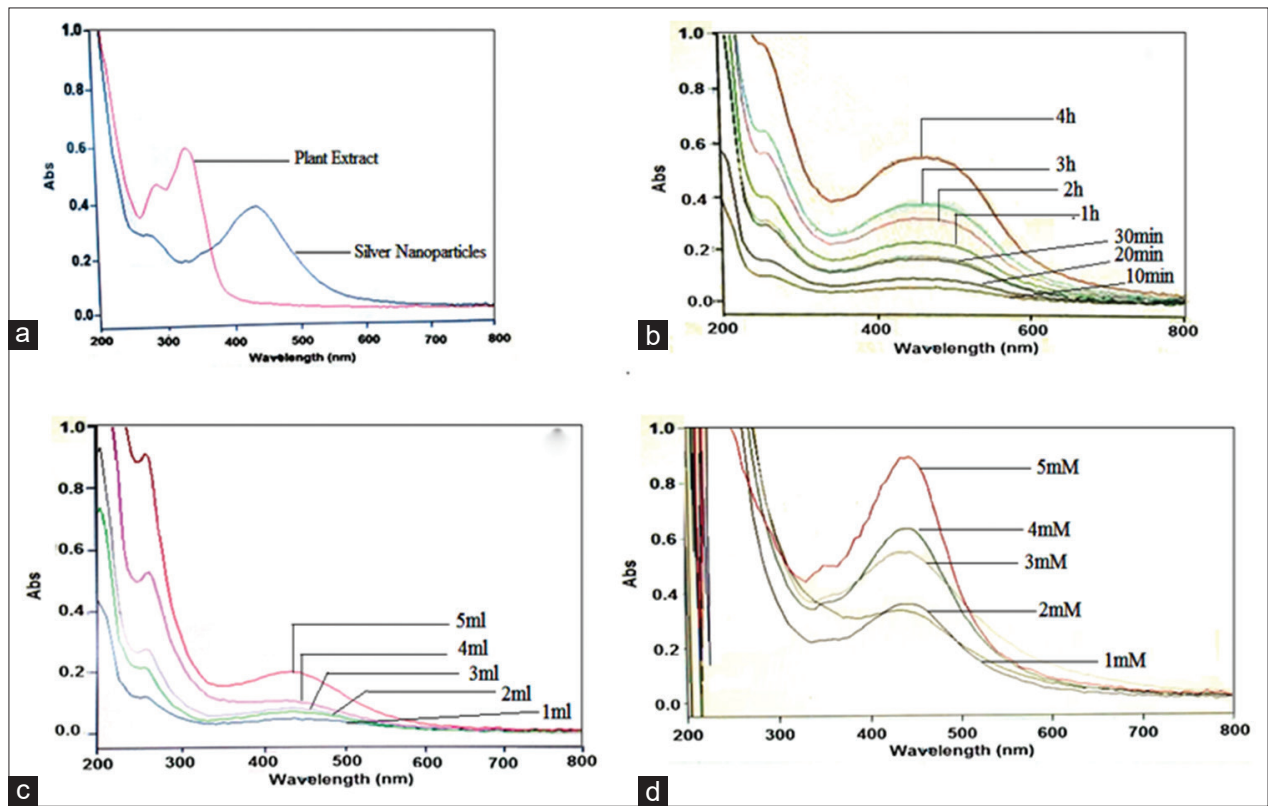

Figure 2: Ultraviolet-visible spectra illustrating absorbance with (a) extract and silver nanoparticles; (b) different time interval; (c) different volume (1-5 mL) of extract; (d) different concentration (1-5 mM) of $\mathrm{AgNO}_{3}$

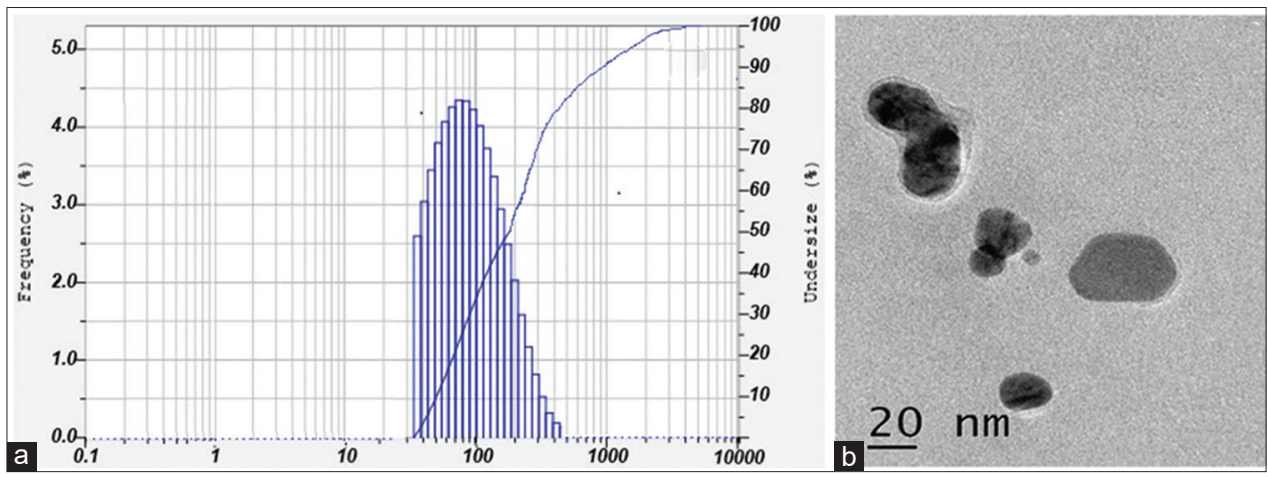

Figure 3: (a) Particle size and (b) transmission electron microscopy image of synthesized silver nanoparticles

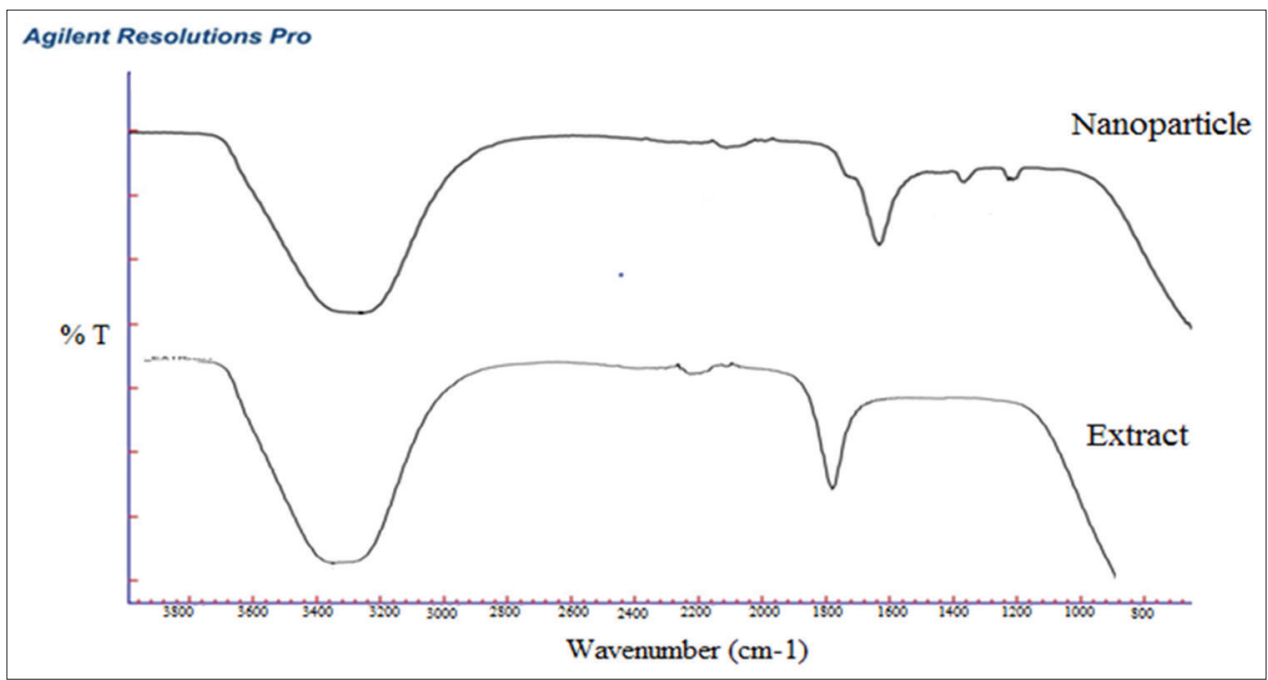

Figure 4: Fourier-transform infrared spectra of extract and synthesized silver nitrate nanoparticles 


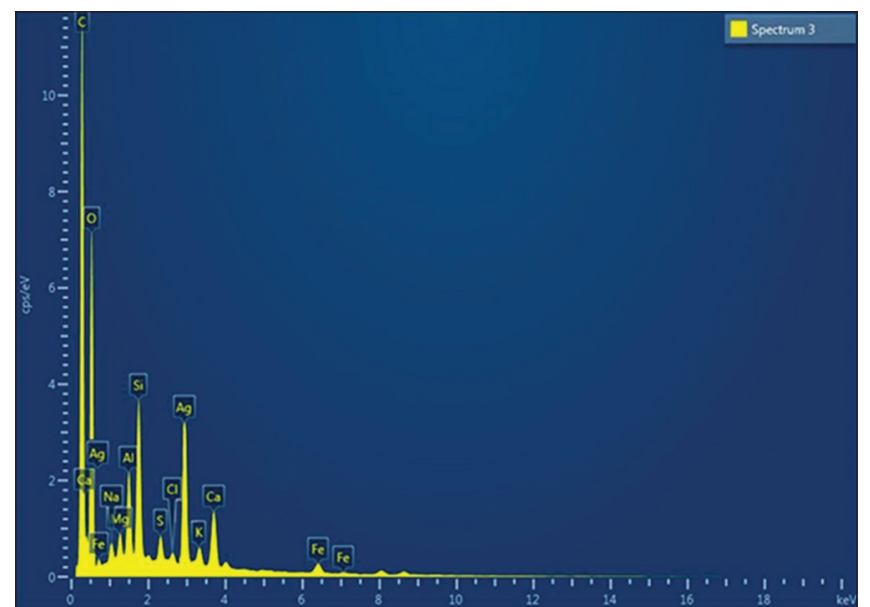

Figure 5: Energy diffraction X-ray spectra of silver nitrate nanoparticles

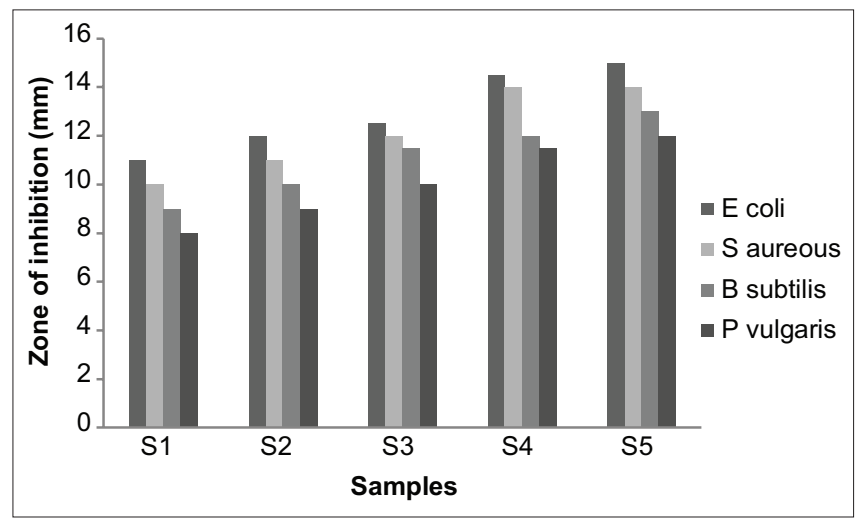

Figure 6: Zone of inhibition ( $\mathrm{mm}$ ) showing $1 \mathrm{~mL}$ extract with $1 \mathrm{mM}$ (S1), $2 \mathrm{mM}$ (S2), $3 \mathrm{mM}$ (S3), $4 \mathrm{mM}$ (S4), and $5 \mathrm{mM}$ (S5) of silver nitrate nanoparticles that the nanoparticles are nanosize and spherical shape [Figure 3b].

\section{FT-IR Study}

FTIR study was performed for both Lantana camera extract and AgNPs [Figure 4]. From the FTIR study, it was confirmed the presence of some functional groups capping the AgNPs. The FTIR of AgNPs, some important peaks were observed at $3454 \mathrm{~cm}^{-1}, 2083 \mathrm{~cm}^{-1}$, and $1113 \mathrm{~cm}^{-1}$. A broad peak at $3454 \mathrm{~cm}^{-1}$ was due to the $\mathrm{OH}$ stretching vibrations of phenol and carboxylic groups present in L. camara leaf extract. The band at $1636 \mathrm{~cm}^{-1}$ corresponds to amide CO stretching and a peak at $2083 \mathrm{~cm}^{-1}$ can be assigned to the alkyne group present in phytoconstituents of extract. The observed peaks at $1113 \mathrm{~cm}^{-1}$ denote -C-OC-linkages or -C-O-bonds. ${ }^{[24]}$

\section{EDAX Study}

EDAX spectra of AgNPs are depicted in Figure 5. The EDAX of AgNPs revealed the presence of Ag, C, and O. However, no signal of $\mathrm{N}$ from $\mathrm{AgNO}_{3}$ was observed. $\mathrm{C}$ and $\mathrm{O}$ signals come from organic compounds of $L$. camara extract, suggesting that some rests of the extract are capping the AgNPs.

\section{Antimicrobial Study}

Nowadays, the number of bacteria showing resistance towards antibiotics and this is the major problem facing in the treatment of various microbial infections. Due to this reason, the present work was undertaken to synthesis nanoparticles with antimicrobial activity from crude aqueous extract of L. camara. The synthesized nanoparticles with the help of
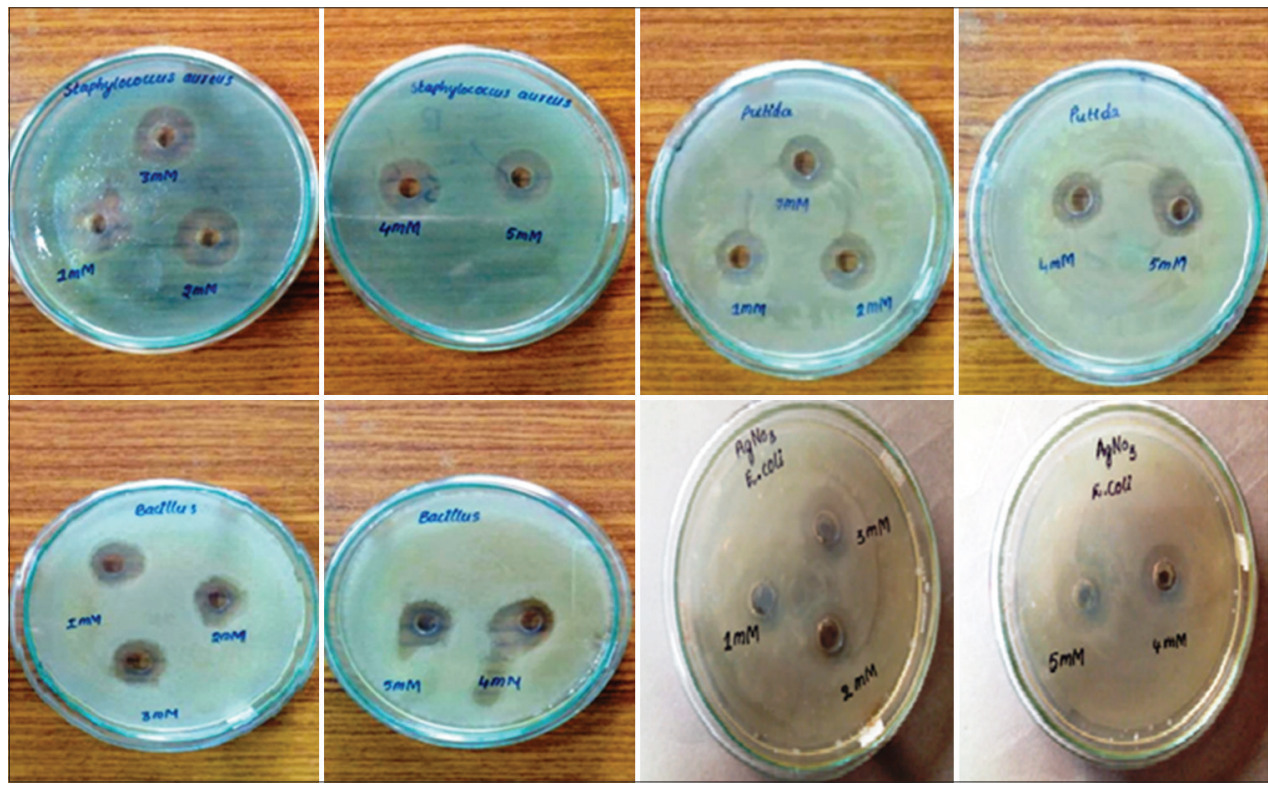

Figure 7: Zone of inhibition of silver nitrate nanoparticles against Staphylococcus aureus, Putida vulgaris, Bacillus subtilis, and Escherichia coli 
Palei: Green synthesis of Silver nanoparticles using leaf extract of Lantana camara

\begin{tabular}{|c|c|}
\hline Samples & Zone of inhibition $(\mathrm{mm})$ \\
\hline Extract & 6 \\
\hline Silver nanoparticles & 10 \\
\hline Standard & 14 \\
\hline
\end{tabular}

plant extract were showing good antimicrobial activity against various Gram-positive (S. aureus) and Gram-negative bacteria $(E$. coli). The antimicrobial activity was using four bacteria, i.e., E. coli, S. aureus, B. subtilis, and P. vulgaris. The zone of inhibition of nanoparticles was compared with the zone of inhibition of standard streptomycin drugs. As the amount of plant extract increases, the activity also increases linearly. Hence, the sample with $5 \mathrm{ml}$ of plant extract and $10 \mathrm{ml}$ of $1 \mathrm{mM}$ silver nitrate as the highest antimicrobial activity compared to other concentrations. With the help of the disc diffusion method, the antimicrobial activity of the prepared nanoparticles was evaluated. The antimicrobial activity of AgNPs is depicted in Figures 6 and 7. The silver nanoparticles showed efficient antimicrobial property compared to others due to their extremely large surface area providing better contact with the cell wall of microorganisms. The zone of inhibition was performed using pure extract, AgNPs, and standard antibiotics (streptomycin). The results revealed that the zone of inhibition was found more as compared to extract. The zone of inhibition results of different samples is depicted in Table 2. Adhesion of AgNPs to the microbial cell wall and membrane due to their electrostatic attraction between negatively charged microbial cell membranes and less negatively charged AgNPs and start the interaction between AgNPs and microorganisms led to a significant decrease in the zeta potential of cell surface in both Gram-positive and Gram-negative bacteria. As a result, the morphological changes in membrane structure are occurred by nanoparticles led to disrupt membrane permeability and finally disrupt the cell integrity and cell death. In addition, the protein part of the outer membrane could interact with AgNPs and create complexes with electron donors such as oxygen, phosphorous, nitrogen, or sulfur atom and cause permanent changes in the cell wall structure. ${ }^{[25]}$

\section{CONCLUSIONS}

Green synthesis of silver nanoparticles was synthesized using aqueous extract of L. camara. The plant extract was obtained by the cold maceration method and it is simple, rapid, ecofriendly, and cost-effectiveness. In terms of reaction time and stability of synthesized nanoparticles, it was considered as an efficient method. L. camara plant extract solutions were used as both reducing and stabilizing agents and synthesized AgNPs were found spherical shape. The antimicrobial activity of synthesized nanoparticles was performed against E. coli, S. aureus, B. subtilis, and P. vulgaris and found that
Gram-negative bacteria were highly inhibited by L. camara silver nanoparticles as compared to Gram-positive bacteria.

\section{REFERENCES}

1. Wang H, Qiao X, Chen J, Ding S. Preparation of silver nanoparticles by chemical reduction method. Colloids Surf A Physicochem Eng Asp 2005;256:111-5.

2. Khaydarov RA, Khaydarov RR, Gapurova O, Estrin Y, Scheper T. Electrochemical method for the synthesis of silver nanoparticles. J Nanopart Res 2009;11:1193-200.

3. Roldan MV, Pellegri N, Sanctis O. Electrochemical method for Ag-PEG nanoparticles synthesis. J Nanopart 2013;2013:524150.

4. Petrucci OD, Hilton RJ, Farrer JK, Watt RK. A ferritin photochemical synthesis of monodispersed silver nanoparticles that possess antimicrobial properties. J Nanomater 2019;2019:9535708.

5. Iravani S, Korbekandi H, Mirmohammadi SV, Zolfaghari B. Synthesis of silver nanoparticles: Chemical, physical and biological methods. Res Pharm Sci 2014;9:385-406.

6. Das VL, Thomas R, Varghese RT, Soniya EV, Mathew J, Radhakrishnan EK. Extracellular synthesis of silver nanoparticles by the Bacillus strain CS 11 isolated from industrialized area. 3 Biotech 2014;4:121-6.

7. Gudikandula K, Vadapally P, Charya MA. Biogenic synthesis of silver nanoparticles from white rot Fungi: Their characterization and antibacterial studies. OpenNano 2017;2:64-78.

8. Logeswari P, Silambarasan S, Abraham J. Synthesis of silver nanoparticles using plants extract and analysis of their antimicrobial property. J Saudi Chem Soc 2015;19:311-7.

9. Pirtarighat S, Ghannadnia M, Baghshahi S. Green synthesis of silver nanoparticles using the plant extract of Salvia spinosa grown in vitro and their antibacterial activity assessment. J Nanostruct Chem 2019;9:1-9.

10. Ahmed S, Saifullah, Ahmad M, Swami BL, Ikram S. Synthesis of sliver nanoparticles using Azadirachta indica aqueous leaf extract. J Radiat Res Appl Sci 2016;9:1-7.

11. Chung IM, Rahuman AA, Marimuthu S, Kirthi AV, Anbarasan K, Padmini P, et al. Green synthesis of copper nanoparticles using Eclipta prostrata leaves extract and their antioxidant and cytotoxic activities. Exp Ther Med 2017;14:18-24.

12. Daphedar A, Taranath TC. Green synthesis of zinc nanoparticles using leaf extract of Albizia saman (Jacq.) Merr. and their effect on root meristems of Drimia indica (Roxb.) Jessop. Caryologia 2018;71:91-102.

13. Aljabali AA, Akkam Y, Al Zoubi MS, Al-Batayneh KM, Al-Trad B, Abo Alrob O, et al. Synthesis of gold nanoparticles using leaf extract of Ziziphus zizyphus and their antimicrobial activity. Nanomaterials 2018;8:174.

14. Kumar PV, Kala SM, Prakash KS. Green synthesis 
of gold nanoparticles using Croton Caudatus Geisel leaf extract and their biological studies. Mater Lett 2019;236:19-22.

15. Yasir M, Singh J, Tripathi MK, Singh P, Shrivastava R. Green synthesis of silver nanoparticles using leaf extract of common arrowhead houseplant and its anticandidal activity. Pharmacogn Mag 2017;13:S840-4.

16. Moodley JS, Krishna SB, Pillay K, Sershen, Govender P. Green synthesis of silver nanoparticles from Moringa oleifera leaf extracts and its antimicrobial potential. Adv Nat Sci Nanosci Nanotechnol 2018;9:015011.

17. Behravan M, Panahi AH, Naghizadeh A, Ziaee M, Mahdavi R, Mirzapour A. Facile green synthesis of silver nanoparticles using Berberis vulgaris leaf and root aqueous extract and its antibacterial activity. Int $\mathrm{J}$ Biological Macromol 2019;124:148-54.

18. Gong $\mathrm{P}, \mathrm{Li} \mathrm{H}, \mathrm{He} \mathrm{X}$, Wang $\mathrm{K}, \mathrm{Hu} \mathrm{J}$, Tan $\mathrm{W}$, et al. Preparation and antibacterial activity of $\mathrm{Fe}_{3} \mathrm{O}_{4} @ \mathrm{Ag}$ nanoparticles. Nanotechnology 2007;18:285604.

19. Naz R, Bano A. Phytochemical screening, antioxidants and antimicrobial potential of Lantana camara in different solvents. Asian Pac J Trop Dis 2013;3:480-6.

20. Khan M, Mahmood A, Alkhathlan HZ. Characterization of leaves and flowers volatile constituents of Lantana camara growing in central region of Saudi Arabia.
Arabian J Chem 2016;9:764-74.

21. Kumar RS, Rajkapoor B, Perumal P. Antitumor and cytotoxic activities of methanol extract of Indigofera linnaei Ali. Asian Pac J Cancer Prev 2011;12:613-8.

22. Veerasamy $R$, Xin TZ, Gunasagaran S, Xiang TF, Yang EF, Jeyakumar N, et al. Biosynthesis of silver nanoparticles using mangosteen leaf extract and evaluation of their antimicrobial activities. J Saudi Chem Soc 2011;15:113-20.

23. Carmona ER, Benito N, Plaza T, Recio-Sanchez G. Green synthesis of silver nanoparticles by using leaf extracts from the endemic Buddleja globosa hope. Green Chem Lett Rev 2017;10:250-6.

24. Banerjee P, Satapathy M, Mukhopahayay A, Das P. Leaf extract mediated green synthesis of silver nanoparticles from widely available Indian plants: Synthesis, characterization, antimicrobial property and toxicity analysis. Bioresour Bioprocess 2014;1:3.

25. Roy A, Bulut O, Some S, Mandal AK, Yilmaz MD. Green synthesis of silver nanoparticles: Biomoleculenanoparticle organizations targeting antimicrobial activity. RSC Adv 2019;9:2673-702.

Source of Support: Nil. Conflicts of Interest: None declared. 